Open Access

\title{
Characterization of the murine macrophage response to infection with virulent and avirulent Burkholderia species
}

Chih-Yuan Chiang ${ }^{1 \dagger}$, Ricky L. Ulrich ${ }^{2 \dagger}$, Melanie P. Ulrich ${ }^{3}$, Brett Eaton ${ }^{1}$, Jenifer F. Ojeda ${ }^{1}$, Douglas J. Lane ${ }^{1}$, Krishna P. Kota ${ }^{4}$, Tara A. Kenny ${ }^{7}$, Jason T. Ladner ${ }^{5}$, Samuel P. Dickson ${ }^{6}$, Kathleen Kuehl', Rahul Raychaudhuri ${ }^{7}$, Mei Sun ${ }^{7}$, Sina Bavari ${ }^{1}$, Mark J. Wolcott ${ }^{8}$, David Covell ${ }^{9}$ and Rekha G. Panchal ${ }^{*}$

\begin{abstract}
Background: Burkholderia pseudomallei (Bp) and Burkholderia mallei (Bm) are Gram-negative facultative intracellular pathogens, which are the causative agents of melioidosis and glanders, respectively. Depending on the route of exposure, aerosol or transcutaneous, infection by $\mathrm{Bp}$ or Bm can result in an extensive range of disease - from acute to chronic, relapsing illness to fatal septicemia. Both diseases are associated with difficult diagnosis and high fatality rates. About ninety five percent of patients succumb to untreated septicemic infections and the fatality rate is $50 \%$ even when standard antibiotic treatments are administered.

Results: The goal of this study is to profile murine macrophage-mediated phenotypic and molecular responses that are characteristic to a collection of Bp, Bm, Burkholderia thailandensis (Bt) and Burkholderia oklahomensis (Bo) strains obtained from humans, animals, environment and geographically diverse locations. Burkholderia spp. $(N=21)$ were able to invade and replicate in macrophages, albeit to varying degrees. All $\mathrm{Bp}(\mathrm{N}=9)$ and four $\mathrm{Bm}$ strains were able to induce actin polymerization on the bacterial surface following infection. Several Bp and Bm strains showed reduced ability to induce multinucleated giant cell (MNGC) formation, while Bo and Bp 776 were unable to induce this phenotype. Measurement of host cytokine responses revealed a statistically significant Bm mediated IL-6 and IL10 production compared to Bp strains. Hierarchical clustering of transcriptional data from 84 mouse cytokines, chemokines and their corresponding receptors identified 29 host genes as indicators of differential responses between the Burkholderia spp. Further validation confirmed Bm mediated II-16, II-10, Tnfrsf1b and II-36a mRNA expressions were significantly higher when compared to Bp and Bt.

Conclusions: These results characterize the phenotypic and immunological differences in the host innate response to pathogenic and avirulent Burkholderia strains and provide insight into the phenotypic alterations and molecular targets underlying host-Burkholderia interactions.
\end{abstract}

Keywords: Burkholderia thailandensis, Burkholderia mallei, Burkholderia pseudomallei, Burkholderia oklahomensis, host response

\footnotetext{
*Correspondence: rekha.g.panchal.civ@mail.mil

${ }^{\dagger}$ Equal contributors

${ }^{1}$ Molecular and Translational Sciences Division, United States Army Medical Research Institute of Infectious Diseases (USAMRIID), Fort Detrick, MD, USA Full list of author information is available at the end of the article
} 


\section{Background}

Burkholderia pseudomallei (Bp) and Burkholderia mallei $(\mathrm{Bm})$ are Gram-negative facultative intracellular pathogens that cause melioidosis and glanders, respectively [1]. Bp causes disease in both humans and animals in the endemic areas of Southeastern Asia and Northern Australia [2, 3]. Infection with Bp can occur via percutaneous inoculation, injection or inhalation of aerosolized bacteria or contaminated fluids [1]. Clinical signs of melioidosis may manifest as flu-like symptoms, pneumonia, or fulminating septicemia that are often fatal [1,4]. Both chronic and acute forms of melioidosis have been reported and the pathogen can colonize a diverse range of tissues including liver, spleen, lung, skin and even the urinary tract.

$\mathrm{Bm}$ is a non-motile, obligate mammalian pathogen that is closely related at the genetic level to the much more diverse species $\mathrm{Bp}[1,5,6]$. The pathogen is endemic among domestic animals in Africa, Asia, the Middle East and Central and South America [6]. Horses are the natural reservoir for $\mathrm{Bm}$, but mules and donkeys are also susceptible [7]. Equine infections are caused by consumption of water or feed contaminated with nasal discharge from infected equines, but a cutaneous form of the disease, known as farcy, also exists. Human infection is primarily caused by direct contact with an infected animal's nasal discharge or skin lesion exudates [8]. In humans, glanders is characterized initially by the onset of fever, rigors and malaise, rapidly leading to pneumonia, bacteremia, pustules and abscesses. Due to the highly infectious nature of $\mathrm{Bp}$ and $\mathrm{Bm}$, in particular for exposure by the aerosol route, both pathogens are considered potential biological warfare threat agents and are classified by the federal select agent program as Tier 1 select agents.

Two other Bp-like species that are closely related, at the genetic and physiological level, that have been reported are Bo and Bt $[9,10]$. Bo was first isolated in Oklahoma in 1973 from the purulent discharge of a pelvic wound from a farmer that was involved in a tractor accident $[9,11]$. Initially, Bo was described as Bp due to the similar metabolic and culture conditions but was differentiated from $\mathrm{Bp}$ using serology and fatty acid composition analysis. Bo is avirulent in hamster and mouse models [12]. Bt CDC2721121 and Bt CDC3015869 were isolated from patient samples in Louisiana and Texas, respectively. Although both Bt CDC2721121 and Bt CDC3015869 originated from human source in the United States of America, they displayed different in vivo pathogenicity profiles. It was demonstrated in Syrian hamster model that Bt CDC2721121 was avirulent whereas Bt CDC3015869 had a virulence capacity that was very similar to the Bt Phuket $4 \mathrm{~W}-1$ strain [12]. Numerous differences between $\mathrm{Bp}$ and $\mathrm{Bt}$ were reported at the genetic, phenotypic, and pathogenic level [12-14]. However, host responses to these pathogens have not been well characterized.

A characteristic feature of $\mathrm{Bp}, \mathrm{Bm}, \mathrm{Bt}$ and Bo pathogens is their ability to infect both phagocytic and nonphagocytic host cells $[15,16]$. The intracellular life cycle of these pathogens involves a coordinated interaction between the host and pathogen proteins that allows the bacteria to adhere and gain entry into the phagosomal compartment of the target cells [17]. Disruption of the phagosomal membrane by Bsa type III secretion system (T3SS) allows the bacteria to escape into the host cytosol, evade host innate responses and killing by autophagy. In the host cytoplasm, bacteria gain motility and spread from cell-to-cell via the polymerization of host actin; a process directed by the bacterial cell surface protein, BimA [18-22]. In contrast, Bt can employ a cryptic (fla2) flagellar system and drive cell-to-cell spread in a BimA independent manner [23]. The type VI secretion system (T6SS) also plays a critical role in bacterial replication and intercellular spread by inducing fusion of the plasma membrane of the infected host cells to form multinucleated giant cells (MNGCs), a hallmark of Burkholderia infection which has been observed in phagocytic, nonphagocytic cell lines and clinical glanders and melioidosis samples. [1, 19]. The expression of the T3SS and T6SS is controlled by mechanisms such as TetR-type regulator, two component systems or quorum sensing [24-26]. Host pathogen recognition receptors (PRRs) and their associated molecules such as Toll-like receptors (TLRs), NOD-like receptors (NLRs) and caspases play a pivotal role in Burkholderia spp. infection [27-34]. Likewise, MCP-1, interferon (IFN)- $\gamma$, TNF- $\alpha$, IL- 6 and IL-10 are key cytokines that modulate $\mathrm{Bp}$ and $\mathrm{Bm}$ infection [28, 35-38]. Host innate immune signaling cascades, however, can be counteracted by bacterial virulence factors. For example, Bp encoded TssM downregulates host inflammatory responses by inhibiting NF- $\mathrm{BB}$ and Type I IFN pathway activation [39], while BopA is important for avoidance of autophagy [26]. Similarly, Cif homolog in Bp (CHBP) also abrogates NF- $\kappa B$ activation by deregulating I $\mathrm{B} \alpha$ degradation and p65 nuclear translocation [40]. Although the interactions between Burkholderia spp. and its hosts have been examined previously, host innate immune responses that are associated with individual strains of Burkholderia spp. is lacking.

The goal of this study was to conduct systematic analyses of the host phenotypic alterations at the cellular level and immunological responses at the molecular level using a diverse collection of Burkholderia spp. obtained from humans, animals, environment and geographically diverse locations. Several strains used in this study have been previously characterized for their pathogenicity in 
vivo in mice or in the Syrian hamster model of infection [12, 41-43]. Measurement of phenotypic responses using conventional colony forming unit (CFU) assays and highcontent imaging (HCI) assay demonstrated all Burkholderia spp. were phagocytosed and replicated within RAW264.7 macrophages. Bo E0147 and Bp 776 failed to induce MNGCs whereas all other Burkholderia spp. induced MNGC to varying degrees. Elevated production of IL-1 $\beta$, TNF- $\alpha$ and KC (murine homolog of human IL-8) cytokines was observed in all Burkholderia spp. infected macrophages. On the contrary, the secretion of IL- 6 and IL-10 was significantly higher in Bm infected macrophages than that of Bp. Hierarchical clustering of the gene expression data from 84 inflammation related genes revealed 29 genes as indicators of differential responses between Burkholderia strains. Further validation studies confirmed a significantly elevated Bm mediated Il-1b, Il-10, Tnfrsf $1 b$ and Il-36a mRNA expressions compared to that with Bp and Bt. Collectively, these multidisciplinary approaches provided a comprehensive assessment of the murine macrophage host response(s) during different stages of infection with a diverse collection of Burkholderia spp.

\section{Results}

Diverse Burkholderia spp. are phagocytized and replicate within RAW264.7 macrophages

A diverse collection of $\mathrm{Bp}(\mathrm{N}=9), \mathrm{Bm}(\mathrm{N}=5)$, Bt $(\mathrm{N}=3)$ and $\mathrm{Bo}(\mathrm{N}=1)$ strains from various geographical locations throughout the world were examined in this study. Available information on the ancestry of the strains along with their source, location, in vivo virulence profile and genome sequences is listed in Table 1. In addition, three mutants of Bm ATCC 23344 strains with deletions in the genes encoding for capsule (Bm ATCC 23344 $\Delta w c b B$ ) or lipopolysaccharide (LPS) (Bm ATCC $23344 \Delta w b i L)$ biosynthesis or both (Bm ATCC 23344 $\Delta w c b B / \Delta w b i L)$ were also evaluated. The ability of each strain to replicate within murine macrophages was determined by incorporating well-established kanamycin $(\mathrm{Km})$ protection assays [44-47]. Intracellular replication within RAW264.7 macrophages was monitored at 2, 4 and $8 \mathrm{~h}$ post infection for each Burkholderia strains. The three Bt strains CDC3015869, Phuket 4 W-1, DW503 and Bo E0147 were internalized and able to replicate in RAW264.7 macrophages (Fig. 1a). Among all the Bp strains that were tested, no statistically significant differences were observed in the uptake and intracellular replication. However, macrophages infected with Bp 776 showed a much-reduced uptake of these bacteria at $2 \mathrm{~h}$ post infection, followed by a robust replication at $4 \mathrm{~h}$ and subsequent drop at $8 \mathrm{~h}$ post infection (Fig. 1b). Based on Transmission electron microscopy (TEM) studies, a much reduced number of the Bp 776 was observed in the cytosol compared to the reference strain Bp K96243 at the late time points (6 and $8 \mathrm{~h}$ ) post infection, while very similar number of bacteria were observed within the membrane bound vesicles for both the strains (Additional file 1: Figure S1). These studies suggest that differential escape rate from endosomal compartment may contribute to the observed phenotype. The uptake of all five Bm strains was similar at the two hour time point. However, at the 4 and $8 \mathrm{~h}$ time points, differences were observed in the intracellular survival and replication but were not statistically significant (Fig. 1c). Furthermore, the intracellular replication of the polar Bm LPS and capsule mutants was similar to that observed for Bm ATCC 23344 (Fig. 1c).

Given the diverse collection of Burkholderia spp. analyzed in this investigation for bacterial uptake and intracellular replication, no distinct patterns linking strains isolated from humans, animals, environment (soil or water) nor geographic location (i.e. Thailand vs. Australia) were observed.

\section{Ability to induce macrophage MNGC formation and exhibit actin tails varies between Burkholderia spp. examined}

A hallmark of Burkholderia spp. infections is the ability of the bacteria to induce MNGC formation of infected macrophages, following cellular uptake and intracellular bacterial replication [17]. In this study, phenotypic screening using HCI was used to quantitate the MNGC phenotype [48]. All the three Bt strains were capable of inducing MNGCs in infected macrophages (Fig. 2a and b). The failure of Bo E0147 to cause MNGCs (Fig. 2a and b; Table 1; Additional file 2: Figure S2) was consistent with the phenotype reported by Wand et al. [44]. Among the five Bm strains, Bm NCTC 3709 and Bm NCTC 10247 exhibited much reduced ability to induce MNGC phenotype (Fig. 3a and b; Additional file 2: Figure S2). Interestingly, Bm 10247 bacteria appear to be trapped in the endocytic vesicles (Fig. 3b), a phenotype not observed following Bm 3709 infection (data not shown). The Bm capsule mutant Bm ATCC $23344 \triangle w c b B$ and double deletion mutant Bm ATCC $23344 \Delta w c b B / \Delta w b i L$ also exhibited reduced ability to induce MNGC compared to the parental strain $\mathrm{Bm}$ ATCC 23344 (Fig. 3a and b; Additional file 2: Figure S2). Five out of the nine Bp strains exhibited reduced ability to induce MNGC when compared with Bp K96243 and Bp E8 (Fig. 4a and b, Table 1 and Additional file 2: Figure S2). The absence of MNGCs in Bp 776 infected RAW264.7 macrophages correlated with reduced uptake and intracellular replication as measured in the CFU assay and reduced endosomal escape rate by TEM.

Several bacterial pathogens, including Shigella, Listeria, Mycobacteria and Burkholderia induce host cell actin tail formation on the bacterial surface to 
Table 1 Bacterial strains used in this investigation and macrophage phenotypes following infection

\begin{tabular}{|c|c|c|c|c|c|c|c|c|c|}
\hline Species and strain & Source & Location & $\begin{array}{l}\text { Year } \\
\text { isolated }\end{array}$ & $\begin{array}{l}\text { Genome } \\
\text { sequenced }\end{array}$ & $\begin{array}{l}\text { Actin } \\
\text { tails }\end{array}$ & MNGC & Uptake & $\begin{array}{l}\text { Intracellular } \\
\text { replication }\end{array}$ & $\begin{array}{l}\text { In vivo } \\
\text { Pathogenicity }\end{array}$ \\
\hline \multicolumn{10}{|l|}{ B. thailandensis } \\
\hline${ }^{\mathrm{a} D W} 503$ & Environment & Thailand & 1998 & Yes & $\begin{array}{l}\text { Yes }[44, \\
66]\end{array}$ & Yes [44] & Yes [44] & Yes [44] & \\
\hline CDC3015869 & Human blood & Texas & 2003 & Yes & Yes [44] & Yes [44] & Yes [44] & Yes [44] & Virulent [12] \\
\hline Phuket 4 W-1 & Water & Thailand & Unknown & Partial & Yes [44] & Yes [44] & Yes [44] & Yes [44] & Virulent [12] \\
\hline \multicolumn{10}{|l|}{ B. oklahomensis } \\
\hline E0147 & $\begin{array}{l}\text { Human } \\
\text { conjunctiva }\end{array}$ & $\begin{array}{l}\text { Georgia, } \\
\text { US }\end{array}$ & 1977 & Yes & No [44] & No [44] & Yes [44] & Yes [44] & Avirulent [12] \\
\hline \multicolumn{10}{|l|}{ B. mallei } \\
\hline NCTC 10229 & Unknown & Hungary & 1961 & Yes & Yes & Yes & Yes & Yes & Virulent [41] \\
\hline NCTC 10247 & Unknown & Turkey & 1960 & Yes & No & Reduced & Yes & Yes & Attenuated [41] \\
\hline NCTC 3708 & Mule & India & 1932 & No & Yes & Yes & Yes & Yes & Virulent [41] \\
\hline NCTC 3709 & Horse & India & 1932 & Yes & Yes & Reduced & Yes & Yes & Virulent [41] \\
\hline ATCC 23344 & Human & China & 1942 & Yes & Yes [67] & Yes [68] & Yes [68] & Yes & Virulent [41] \\
\hline${ }^{b} 23344 \Delta w c b B$ & UGA & China & 1942 & Yes & ${ }^{c} N T$ & Reduced & Yes & Reduced & \\
\hline${ }^{b} 23344 \Delta w b i l$ & UGA & China & 1942 & Yes & ${ }^{c} N T$ & Yes & Yes & Reduced & \\
\hline $\begin{array}{l}{ }^{\text {b23344 }} \Delta w \text { bil/ } \\
\Delta w c b B\end{array}$ & UGA & China & 1942 & Yes & ${ }^{c} \mathrm{NT}$ & Reduced & Yes & Reduced & \\
\hline \multicolumn{10}{|l|}{ B. pseudomallei } \\
\hline 576 & Human Blood & Thailand & Unknown & Yes & Yes [44] & Reduced & Yes [44] & Yes [44] & \\
\hline MSHR305 & Human Brain & Australia & 1994 & Yes & Yes & Yes & Yes & Yes & Virulent [43] \\
\hline 295 & Soil & Australia & Unknown & No & Yes & Reduced & Reduced & Reduced & \\
\hline 713 & Ulcer & Australia & Unknown & No & Yes & Reduced & Yes & Yes & \\
\hline $1026 b$ & Blood & Thailand & 1993 & Yes & Yes [69] & Reduced & Yes [69] & Reduced & Virulent [43] \\
\hline DD503 & Soil & Australia & Unknown & No & Yes & Reduced & Reduced & Reduced & \\
\hline 776 & Blood & Australia & Unknown & No & Yes & No & Reduced & Reduced & \\
\hline E8 & Soil & Thailand & 1990 & Yes & Yes [21] & Yes & Yes [21] & Yes [21] & \\
\hline K96243 & Human & Thailand & 1996 & Yes & Yes [44] & Yes [48] & Yes [44] & Yes [44] & Virulent [42] \\
\hline
\end{tabular}

Table 1 Bacterial strains used in this investigation and RAW264.7 macrophage phenotypes following infection. Explanations of column headings are: Species and strain: the species and strain that are used in this study; Source, location and year isolated: the source, location, and year that the corresponding strain was first identified; Genome Sequenced: the availability of the gene sequencing information for the corresponding strain; Actin tails, the ability of the corresponding strain to polymerize host actin and exhibit actin tails on the bacterial surface; MNGC, ability of the corresponding strain to induce macrophage MNGC; uptake and intracellular replication: ability of the corresponding strain to be taken up by macrophages and replicate intracellularly; in vivo pathogenicity, pathogenicity is determined by survival of mice and Syrian hamsters challenged with indicated Burkholderia spp.

${ }^{a}$ Derived from B. thailandensis E264; $\Delta(a m r R-o p r A)\left(\mathrm{Km}^{\mathrm{s}} \mathrm{Gm}^{\mathrm{s}} \mathrm{Sm}^{\mathrm{s}}\right) ; r p s L\left(\mathrm{Sm}^{\mathrm{r}}\right)$ [10]

bobtained from the laboratory of Mark Schell, University of Georgia nUGA) and derived from B. mallei ATCC 23344

${ }^{\mathrm{C}} \mathrm{NT}$, not tested in the study

facilitate cell-to-cell spread, while evading the host immunological responses and promoting intracellular replication [20]. The three $\mathrm{Bt}$ and four $\mathrm{Bm}$ strains as well as all the nine Bp strains (Figs. 2b, $3 \mathrm{~b}$ and $4 \mathrm{~b}$ and Table 1) tested in this study were capable of inducing host actin polymerization and exhibiting actin tails on the bacterial surface. However, Bo E0147 and Bm NCTC 10247 strains failed to exhibit actin tail formation on bacterial surface following infection (Table 1).
Burkholderia spp. infected RAW264.7 macrophages induce differential cytokine responses

Previously, elevated IL-1 $\beta$, IL-8, IL-6, TNF- $\alpha$ and IFN- $\gamma$ concentrations have been associated with death among patients with melioidosis [49-51]. In addition, IL-10, a potent anti-inflammatory cytokine, was thought to have an important suppressive immune-regulatory role in the early stages of Bp infection [52]. The ability of Burkholderia spp. to modulate IL-1 $\beta$, TNF- $\alpha, \mathrm{KC}$, IL- 6 and IL-10 production in RAW264.7 macrophages was investigated. All twenty-one 


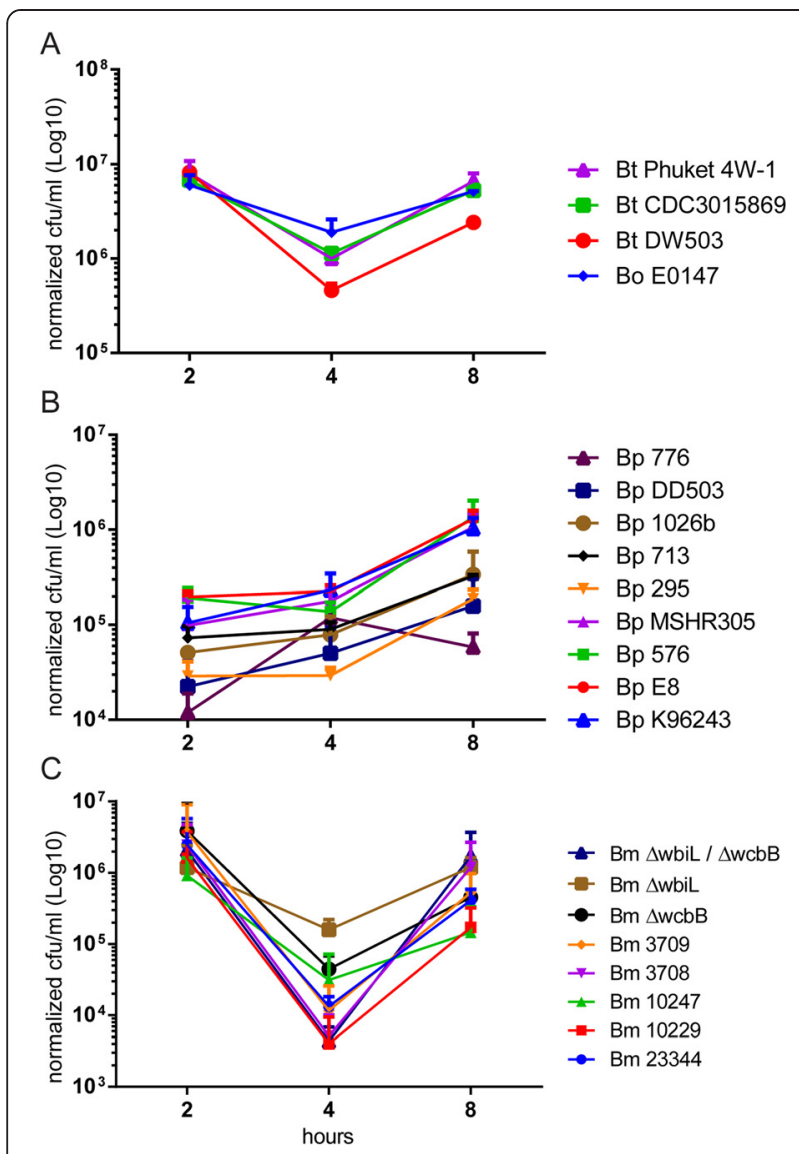

Fig. 1 Quantitation of Burkholderia spp. intracellular replication. RAW264.7 macrophages were infected with the indicated Burkholderia spp. at a MOI of 10. Two hours post infection, kanamycin was added to reduce the growth of extracellular bacteria. Viable bacteria a) Bt and $\mathrm{Bo}$; b) $\mathrm{Bp}$; c) Bm were quantified at the indicated time points using CFU assays. All data shown is representative of two replicates per strain per time point, and performed on two independent days. Data was normalized and averaged by actual $\mathrm{MOI}$

strains of Burkholderia spp. induced IL-1 $\beta$, TNF- $\alpha$ and KC production (Fig. 5a and Additional file 3: Figure S3). Notably, RAW264.7 macrophages infected with Bm spp. resulted in significantly elevated levels of IL-6 and IL-10 when compared with Bp spp. infections (Fig. 5b). The production of IL-6 was reduced in RAW264.7 macrophages infected with mutant Bm strains (Bm ATCC 23344 $\Delta w c b B$, $\Delta w b i L / \Delta w c b B$ and $\Delta w b i L)$ compared to cells infected with the parental Bm ATCC 23344 strain. The observed difference in IL-6 and IL-10 production between Bm and Bp infected macrophages suggests the existence of distinct underlying molecular signaling cascades.

\section{Differential expression of inflammation related genes in Burkholderia spp. infected RAW264.7 macrophages}

Genes encoding chemokines and pro-inflammatory cytokines are critical mediators of intracellular bacterial infection for in vivo and in vitro systems. To determine if the different Burkholderia spp. modulate common or unique host immune responses, we examined the transcriptional profile of 84 inflammation related genes from RAW264.7 macrophages infected for 4 or $8 \mathrm{~h}$ with the diverse Burkholderia strains. Hierarchical clustering of the gene expression data separated Burkholderia strains into eleven sub-clades, with distinct segregation between the early ( $4 \mathrm{~h}$ and representing clades $1-5)$ and the late (8 $\mathrm{h}$ and representing clades 6-11) infection times (Fig. 6 and Additional file 4: Table S1). Sub-clustering within the early and late exposure times separated for the most part the Bm, Bp and Bt strains. Pairwise comparisons of host gene expressions at each exposure time were used to identify differences in the host responses to specific $\mathrm{Bp}, \mathrm{Bm}$ and Bt species. A Student's t statistic was computed and clustered heat map generated for the three pairwise gene expressions; $\mathrm{Bp}-\mathrm{Bt}, \mathrm{Bm}-\mathrm{Bt}$ and $\mathrm{Bm}-\mathrm{Bp}$, using their corresponding pairwise differences between averaged gene expressions. Twenty-nine host genes were identified as indicators of differential responses between the Burkholderia spp. (Fig. 7a and Additional file 5: Table S2). Statistical analysis demonstrated that Bm collectively induced significantly higher expression of a gene cluster than $\mathrm{Bp}$ and $\mathrm{Bt}$ at $8 \mathrm{~h}$ post infection. The expression levels of a subset of genes, Tnfrsf $1 b, I l-1 b, I l$ $36 a$ and $I l-10$ were validated by real-time PCR using independently prepared samples (Fig. 7b). With the exception of Bt CDC3015869, the Bm strains collectively showed statistically significant increased expression of Tnfrsf $1 b, I l-1 b, I l-36 a$ and $I l-10$ genes compared to the $\mathrm{Bp}$ and the two Bt strains. These results indicate that gene-based differences for Burkholderia species are evident within the different components of the inflammatory response.

\section{Discussion}

In vitro characterization of host responses to Burkholderia infection at both the phenotypic and molecular level provides a rapid approach to gain insight into the intracellular lifestyle of both pathogenic and avirulent Burkholderia strains. We characterized the host phenotypic responses by measuring each Burkholderia strain's capacity to a) invade and replicate in macrophages, b) induce host actin polymerization on bacterial surfaces and c) induce RAW264.7 macrophage MNGC formation. All Burkholderia spp. invaded and replicated within RAW264.7 macrophages, albeit to varying degrees. Quantitation of MNGC formation in infected macrophages revealed several Bm (Bm NCTC 3709, Bm NCTC 10247) and Bp (Bp 576, Bp 295, Bp 713, Bp 1026b and Bp DD503) strains to exhibit a reduced capability of inducing this phenotype. There was no observed correlation between intracellular bacterial replication and reduced number of MNGCs or actin tails. In vitro, Bo E0147 strain is 

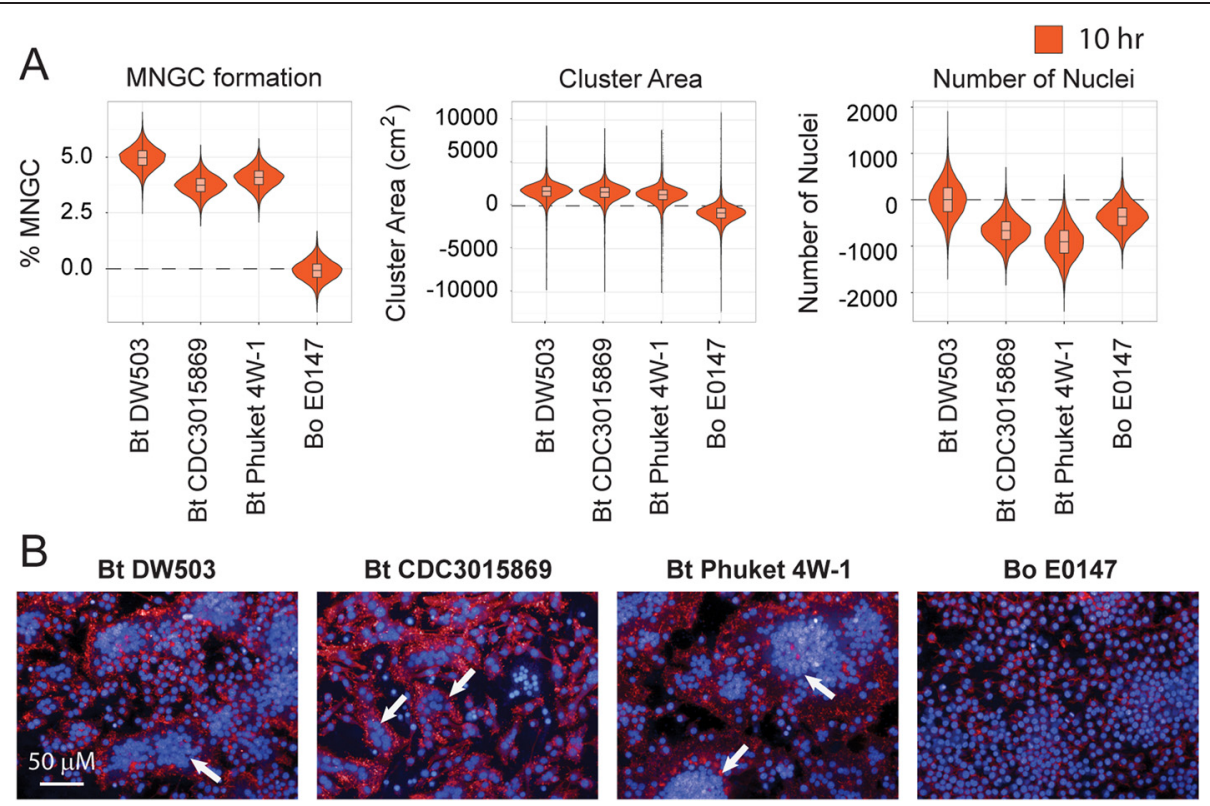

Fig. 2 Quantitation of Bt and Bo induced MNGC formation. RAW264.7 macrophages were infected with indicated Bt and Bo strains at a MOI of 30. Ten hours post infection cells were fixed and stained with hoechst dye and phalloidin-568. a) Violin plots representing the quantitation of cellular attributes of the cluster population (i.e.: MNGC formation, Cluster Area and number of nuclei) as measured by MNGC image analyses procedure. All data was normalized to uninfected control. b) Representative confocal images of MNGC formation. Nuclei are pseudocolored blue (hoechst dye) and actin pseudocolored red (Phalloidin). Scale bar - $50 \mu \mathrm{m}$. All data shown is representative of six replicates per plate, three plates per day and performed on three independent days. White arrows indicate MNGCs

not capable of inducing MNGC phenotype, an observation similar to that reported by Wand et al. [44], and which in part could be due to its inability to polymerize host actin and thereby prevent the bacterial cell-to-cell spread. Prior published studies suggest that the lack of WASP homology 2 (WH2) domain in BimA and the absence of T3SS transcription regulators, BPSS1553 (bprP) and BPSS1554 (bprQ), in Bo may contribute to the observed phenotypes $[44,53]$. Intriguingly, Bp 776 did not induce macrophage MNGC formation despite the detection of actin tail on the bacterial surface. Due to the lack of genome sequence information for Bp 776, the genome integrity cannot be determined and hence difficult to correlate phenotype with genotype. Bm NCTC 10247 did not exhibit actin tails, were trapped in endocytic compartments and showed much reduced capacity to induce MNGCs. Functional studies to correlate the Bm 10247 phenotype to genotype are ongoing.

Intrinsic differences at the cellular level may contribute to differences in host susceptibility to Burkholderia infection. For example, prior published studies have shown that C57BL/6 mice are 10 to 100 fold more resistant to Bp infection compared to BALB/c mice $[52,54,55]$. Furthermore, bone marrow-derived macrophages from C57BL/6 mice can clear the bacteria more efficiently compared to those obtained from BALB/c mice. In this study, since a uniformed in vitro system such as the RAW264.7 macrophages was used to characterize the host responses to Burkholderia spp. infection, differences in the bacterial genome composition or mutations may contribute to the observed cellular phenotypes. In an attempt to correlate the pathogen induced host phenotypes to mutations in known bacterial virulence factors, comparative genomics analysis was conducted for the $\mathrm{Bm}$ and $\mathrm{Bp}$ strains whose genome sequences were available. A little over 60 loci were examined in each species (Additional file 6: Table S3). These encompassed loci that were important for the expressions of T3SS-3, T6SS-1, actin motility, and several regulators of these systems including VirAG, BspR, BprP, BprQ, BsaN, and RpoS. Putative orthologs for these virulence genes were identified in all strains regardless of phenotype, and in most cases, the genes were $100 \%$ identical at the nucleotide-level. Even in cases where variability was detected, we failed to identify any mutations that would likely result in the loss of function. Notably, Bp 576 showed deletions in one locally repetitive region amounting in 99 deleted bases in BPSS1493 (a gene associated with actin motility and just downstream from $\operatorname{bimA}$ ), as compared to Bp K96243 (data not shown). Although this deletion does not disrupt the coding frame, the functional consequences of this mutation need to be empirically determined. In addition, we cannot exclude the impact of 37 in silico identified T3SS proteins that may contribute to the virulence of Burkholderia spp. [56, 57]. The genome 


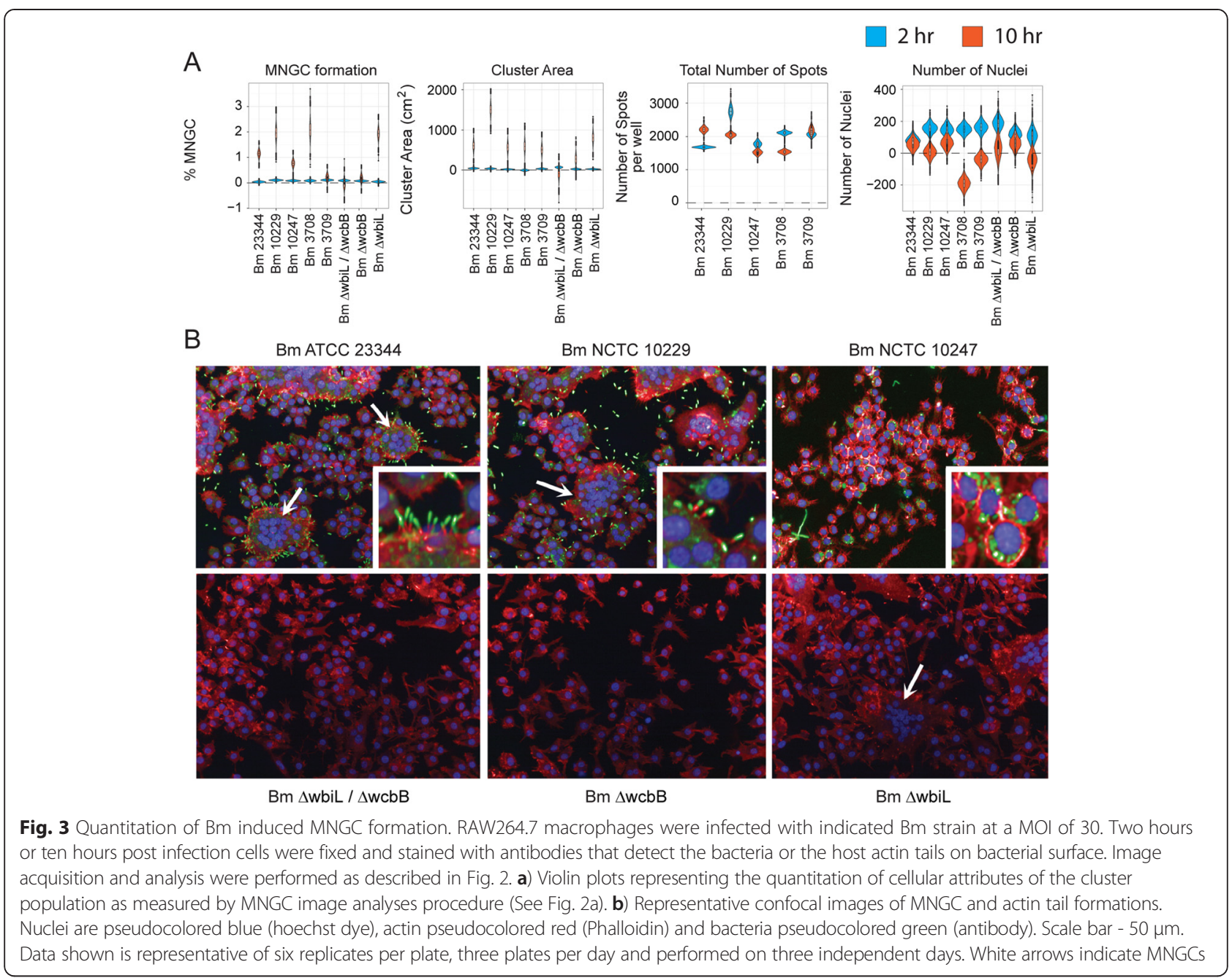

integrity and the function of these putative factors require further investigation. Importantly, to generate a strong correlation between virulence and MNGC/actin tail formation, a larger number of the Burkholderia strains will need to be incorporated for in vivo virulence and in vitro phenotype studies.

Cytokines produced during the course of Burkholderia infection behave like a double-edged sword. Select cytokines, while important for resistance to Burkholderia infection, are also potential contributors to immunopathology [52]. Infection of RAW264.7 macrophages with the different Burkholderia spp. resulted in uniform increased secretion of IL- $1 \beta$, TNF- $\alpha$ and IL- 8 . However, macrophages infected with Bm strains showed a statistically significant increased production of IL-6 and IL-10 compared to Bp strains. The induction of IL- 6 cytokines was also observed in non-human primate (NHP) peripheral blood mononuclear cells (PBMCs) infected with $\mathrm{Bm}$ or stimulated with Bm derived LPS [58]. Further, gene expression profiling of eighty-four inflammation related genes identified 29 host genes that exhibited differential responses between the Burkholderia strains. Validation studies confirmed Bm mediated increased expression of $I l-1 b$, Il-10, Tnfrsf $1 b$ and $I l-36 a$ host genes compared to Bp.

In addition to the virulence factors, the $\mathrm{Bp}$ genome encodes about 627 genes on chromosome 1 and 819 genes on chromosome 2 that are either not present or variant in $\mathrm{Bm}$. A majority of these genes function in amino acid, nitrate, tagatose, allantoin and cellobiose metabolism. In addition, several genes (e.g.: Succinate-semialdehyde dehydrogenase, Glycerate kinase 1, Succinate-semialdehyde dehydrogenase, D-3-phosphoglycerate dehydrogenase, etc.) are involved in glycolysis and tricarboxylic acid (TCA) cycle [41]. Recent studies have revealed that metabolites can regulate innate immune responses [59]. For example, stimulation of macrophages by LPS, a component of the outer membrane of Gram-negative bacteria, upregulates succinate, a TCA cycle intermediate. Inhibition of prolyl hydroxylases (PHDs) activity by succinate stabilizes HIF-1 $\alpha$, a transcription factor that binds to 


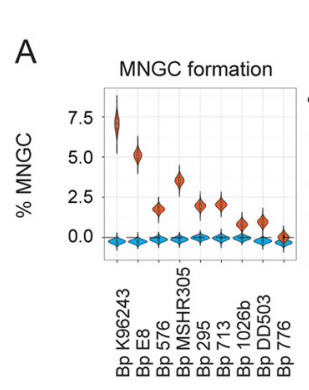

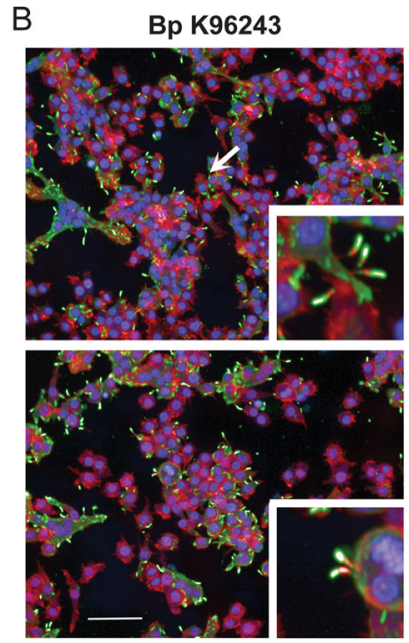

Bp MSHR305

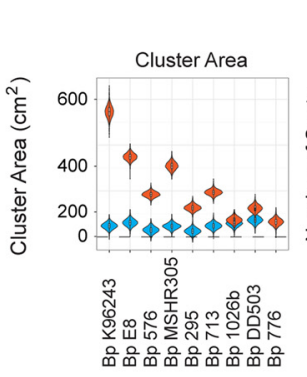

(1)

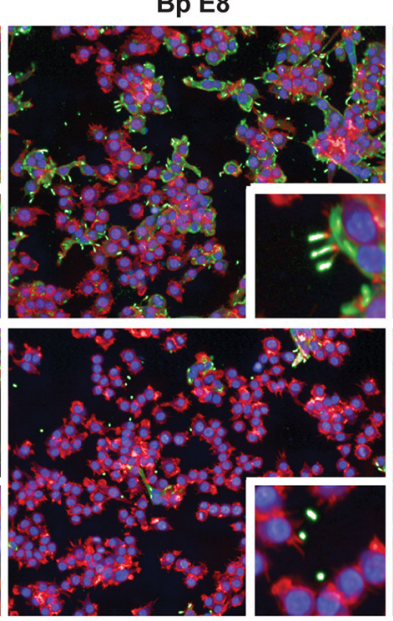

Bp 776

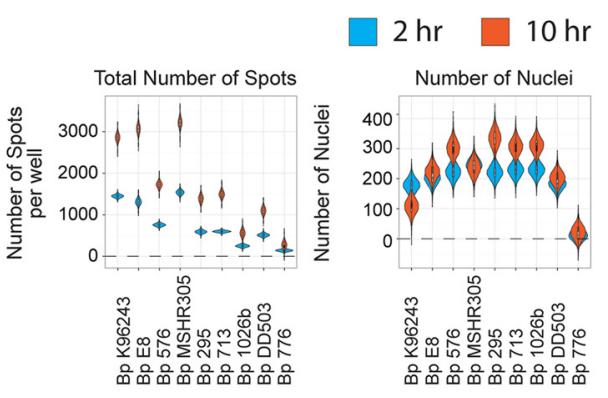

Bp DD503

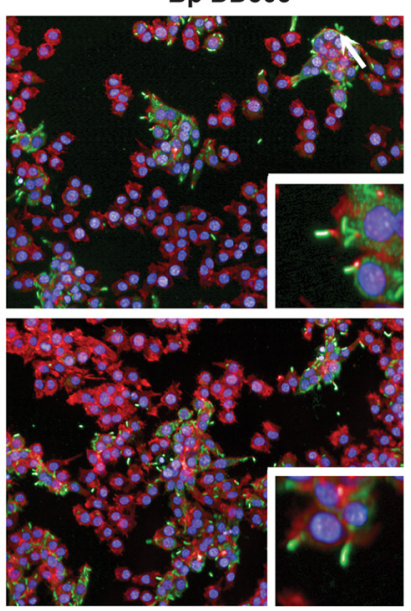

Bp 295

Fig. 4 Quantitation of Bp induced MNGC formation. RAW264.7 macrophages were infected with indicated Bp strain at a MOI of 30. Two hours or ten hours post infection cells were fixed and stained with antibodies that detect the bacteria or the host actin tails on bacterial surface. Image acquisition and analysis were performed as described in Fig. 2. a) Violin plots representing the quantitation of cellular attributes of the cluster population as measured by MNGC image analyses procedure. $\mathbf{b})$ Representative confocal images of MNGC and actin tail formations. Nuclei are pseudocolored blue (hoechst dye), actin pseudocolored red (Phalloidin) and bacteria pseudocolored green (antibody). Scale bar - 50 um. Data shown is representative of six replicates per plate, three plates per day and performed on three independent days. White arrows indicate MNGCS

the IL-1 $\beta$ promoter and triggers IL-1 $\beta$ production [59]. We hypothesize that the fundamental differences in the metabolic capabilities between Bm and Bp may affect the host metabolite profile and delineate the observed cytokine and gene expressions levels.

Bp also activates host innate immune responses through two NLRs, NLRC4 and NLRP3 [47]. Bp mediated NLRC4 activation induces pyroptosis that restricts intracellular bacterial growth whereas its engagement to NLRP3-inflammasome promotes IL-1 $\beta$ production that may lead to tissue damage. NLRP3 has been suggested in multiple metabolic diseases [60]. In addition to pathogen associated molecular patterns, NLRP3 can also be activated by metabolic "danger" signals such as high levels of glucose, saturated fatty acids and ceramides that are typically associated with obese or diabetic individuals. Since diabetes is a major risk factor of melioidosis, comparative analysis to characterize Bp vs. $\mathrm{Bm}$ mediated cytokine and gene expression changes will provide insight toward understanding of innate immunity and disease progression.

\section{Conclusions}

These studies provide a detailed analysis, at the cellular and immunological level, the ability of a diverse range of pathogenic and avirulent Burkholderia strains to infect and trigger host immune responses in murine RAW264.7 macrophages. However, multiple challenges remain, as identifying gene sets or phenotypic alterations that can be used to profile the diverse Burkholderia strains or species and generate characteristic molecular or cellular signatures, as described in this study, still require further investigation and validation. Furthermore, a large number of the Burkholderia strains will need to be evaluated for statistical analysis that will help generate characteristic signature profile linking the observed cellular or molecular phenotype to 

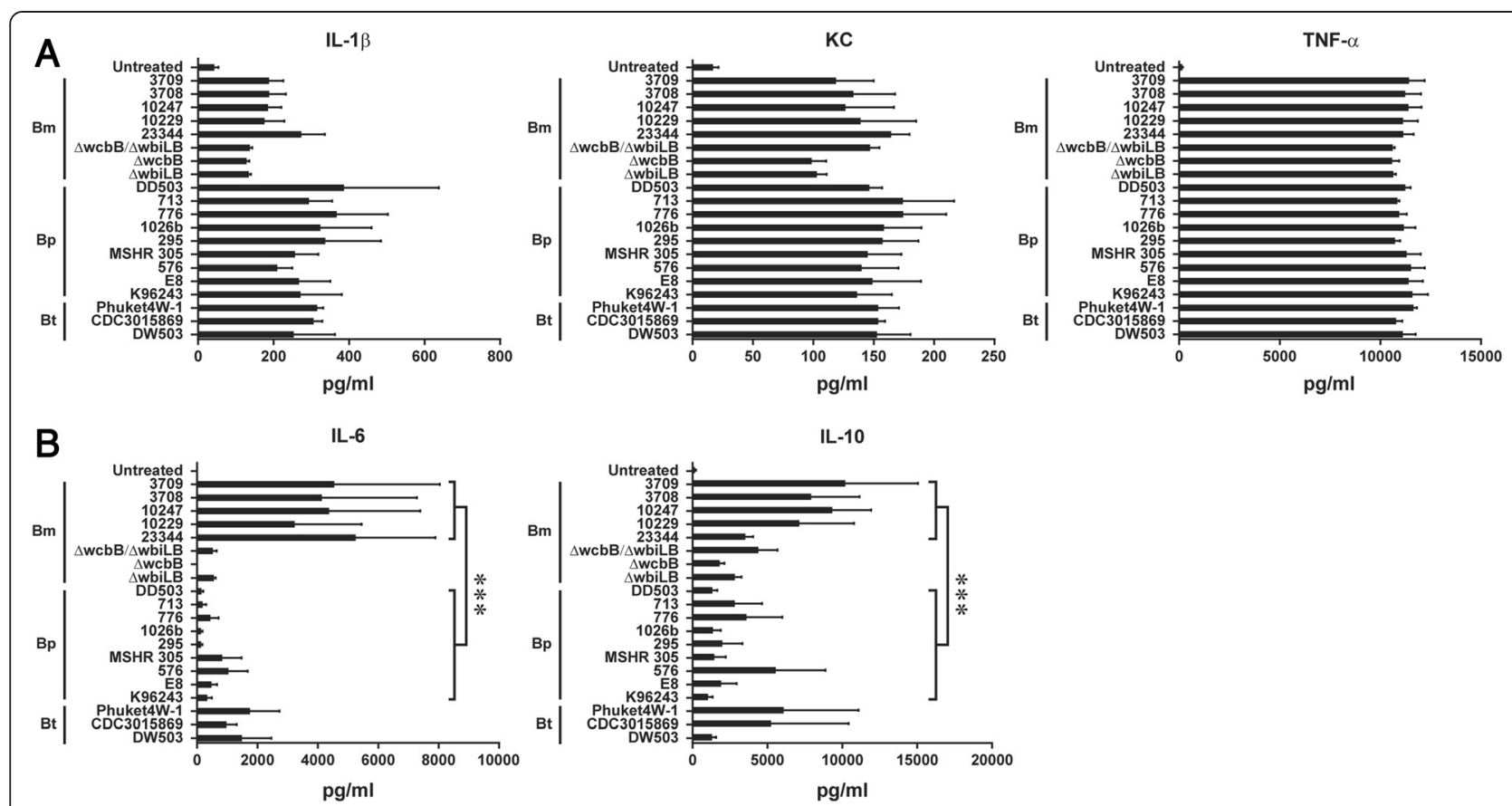

Fig. 5 Profiling inflammation related cytokine production in RAW264.7 macrophages infected with Burkholderia spp. a \& b) RAW264.7 macrophages were infected with listed Burkholderia spp. at a MOl of 10. Eight hours post infection, the supernatants were harvested and the amount of indicated cytokines was quantified. Unpaired Student's t-test was performed to evaluate the statistical significance between the species (*** represent $p$ value smaller than 0.001). All data shown is representative of $n=5$ experiments

the source or geographical location at either the strain or species level or the virulence.

\section{Methods}

Bacterial strains and macrophage culture

Burkholderia strains used in this investigation were obtained from the Department of Defense Unified Culture Collection (UCC) maintained at USAMRIID. Bm ATCC 23344 $\Delta w c b B$, Bm ATCC 23344 $\Delta w b i L$ and Bm ATCC 23344 $\Delta w b i L / \Delta w c b B$ were obtained from the laboratory of Mark Schell, University of Georgia. Detailed information about these strains can be found in Table 1 and Additional file 7: Table S4. Burkholderia cultures were maintained on Luria Broth (LB) plates with $1.5 \%$ agar or on sheep blood agar (SBA) plates containing $5 \%$ sheep blood. All Bm strains were cultured on LB containing $4 \%$ glycerol. Agar plates were incubated at $37{ }^{\circ} \mathrm{C}$ and broth cultures were grown at $37{ }^{\circ} \mathrm{C}$ with shaking at $250 \mathrm{rpm}$. Bacterial concentrations were quantified using $\mathrm{OD}_{600}$ readings and diluted using a conversion factor of $5 \times 10^{8} \mathrm{CFU} / \mathrm{ml}$ per unit of optical density at $600 \mathrm{~nm}$ [61]. All studies using viable $\mathrm{Bp}$ and $\mathrm{Bm}$ strains were performed using biosafety level three conditions.

RAW264.7 macrophage cell line (ATCC, Manassas, VA) were maintained at $37{ }^{\circ} \mathrm{C}$ with $5 \% \mathrm{CO}_{2}$, in DMEM (Life Technology, Carlsbad, CA) containing $10 \%$ fetal bovine serum (FBS) (Hyclone, Logan, UT), 1 \% nonessential amino acids (Sigma-Aldrich, St. Louis, MO), and $1 \%$ glutamax (Life Technology, Carlsbad, CA).

\section{Colony forming unit (CFU) assay to quantify bacterial uptake and intracellular replication}

RAW264.7 macrophages were seeded in 96 well $\left(2 \times 10^{4}\right.$ cells/well for Bm infections) or 24 well $\left(2.5 \times 10^{5}\right.$ cells/ well for $\mathrm{Bp}, \mathrm{Bt}$ and $\mathrm{Bo}$ ) tissue culture plates and incubated overnight at $37{ }^{\circ} \mathrm{C}$ with $5 \% \mathrm{CO}_{2}$. Bacterial survival for each strains was performed using a modified $\mathrm{Km}$ protection assay [62]. RAW264.7 macrophages were infected by Burkholderia strains with a multiplicity of infection (MOI) of 10. Two hours post-infection, macrophages were washed three times with $\mathrm{PBS}$ and either lysed using $0.1 \%$ (vol/vol) Triton X-100 (Sigma-Aldrich, St. Louis, MO) or incubated with pre-warmed DMEM containing $10 \% \mathrm{FBS}$ and $250 \mu \mathrm{g} / \mathrm{ml}$ of $\mathrm{Km}$. At 4 and $8 \mathrm{~h}$ post-infection, macrophages were washed two times with PBS and lysed with $0.1 \%$ ( $\mathrm{vol} / \mathrm{vol})$ Triton X-100. Serial dilutions of the lysates were performed and plated onto SBA plates. After incubation for $48 \mathrm{~h}$ at $37{ }^{\circ} \mathrm{C}$, colonies were counted and $\mathrm{CFU} / \mathrm{ml}(\mathrm{CFU} / \mathrm{ml}$ is the number of colonies on the plate multiplied by the dilution factor and adjusted to a volume of $1 \mathrm{ml}$ ) was computed by normalizing to input CFUs based on colony counts. 


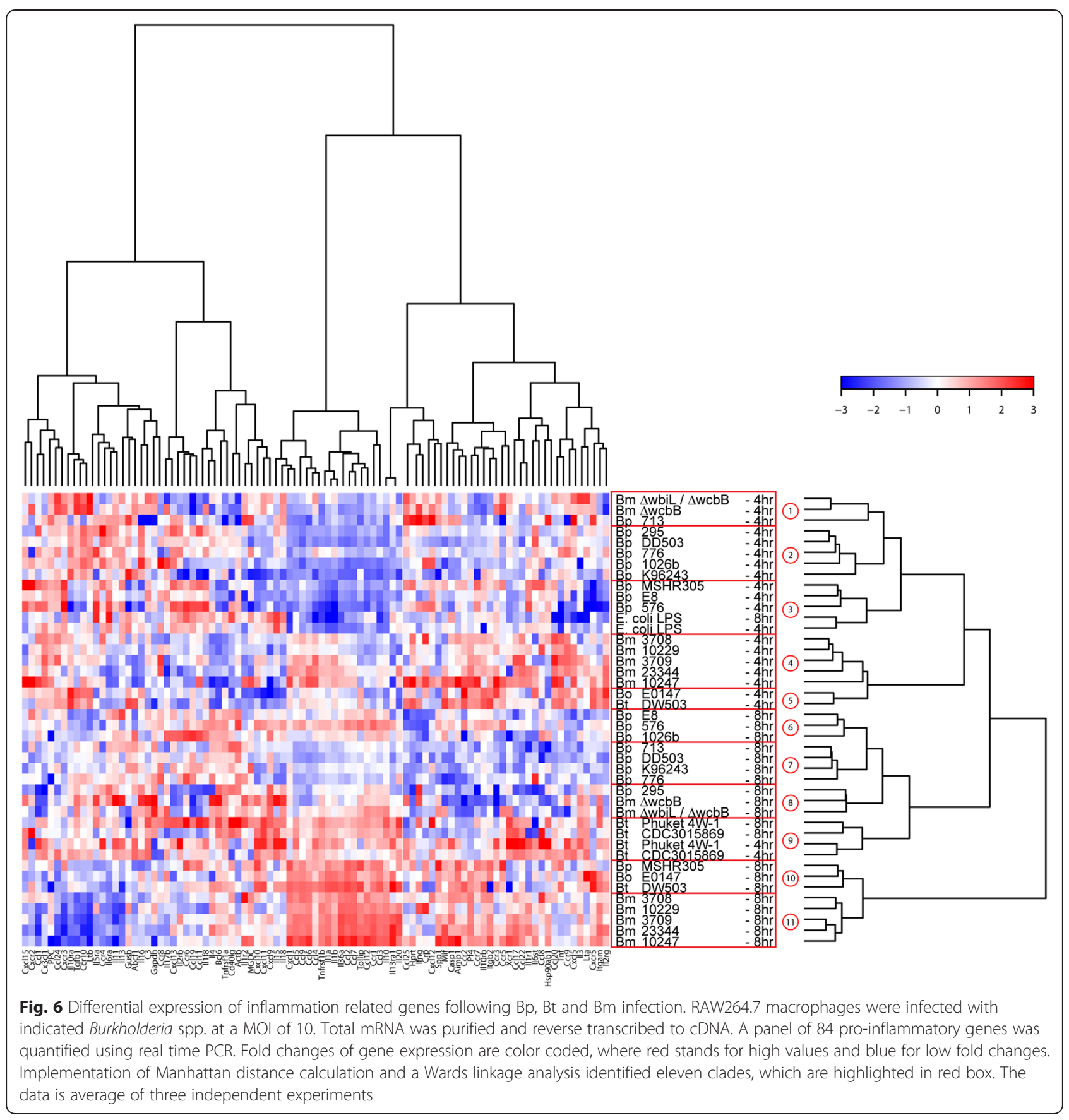

\section{Immuno-fluorescence staining}

RAW264.7 macrophages were infected by Burkholderia spp. at a MOI of 10 for ten hours. Macrophages were washed twice with PBS and fixed with formaldehyde. Antibodies AB-BURK-P-MAB3 (ABE\#393, Critical Reagents Program, Frederick, MD), AB-G-BURK-M (ABE\#327, Critical Reagents Program, Frederick, MD) and phalloidin-568 (Life Technology, Carlsbad, CA) were used to detect Bp, $\mathrm{Bm}$ and actin filaments, respectively. Images were acquired using an Opera confocal reader (model 3842-Quadruple Excitation).
Methods for quantifying bacteria and MNGCs were described previously $[48,63]$. Briefly, to detect and quantify cell associated and internalized bacteria, Acapella's Spot Detection algorithm was used. For MNGC quantitation, RAW264.7 macrophages whose nuclei are at a distance of $0-3$ pixels were considered as part of a single cluster. Cellular attributes of the cell population were then imported (as sums) into the corresponding clusters and the number of nuclei per cluster attribute calculated. Clusters were then further classified into a MNGC subpopulation based on the number of nuclei present in the 


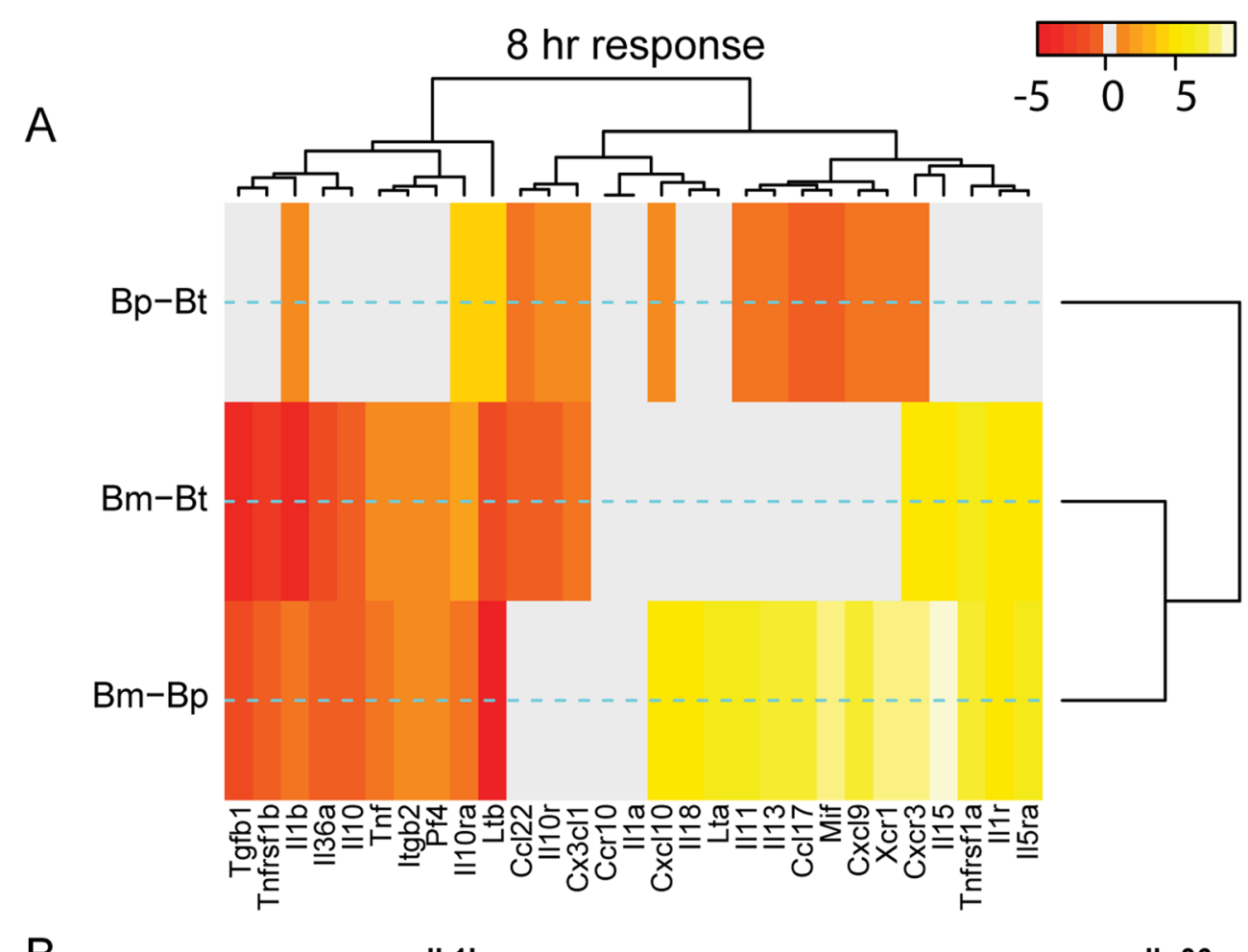

B

II-1b

II -36a
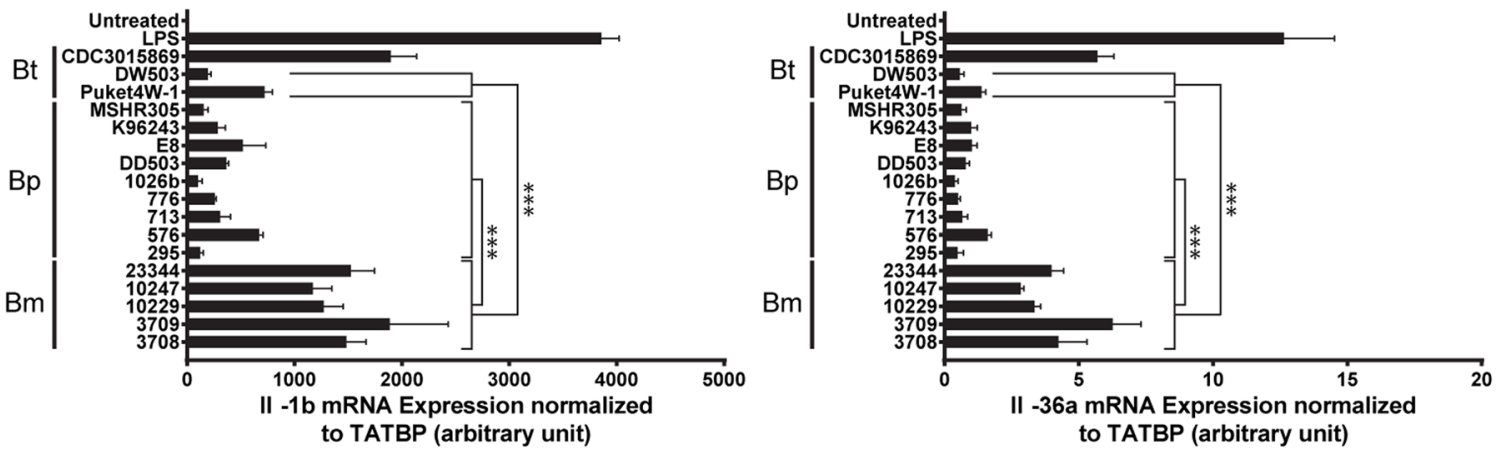

II -10

Tnfrsf1b
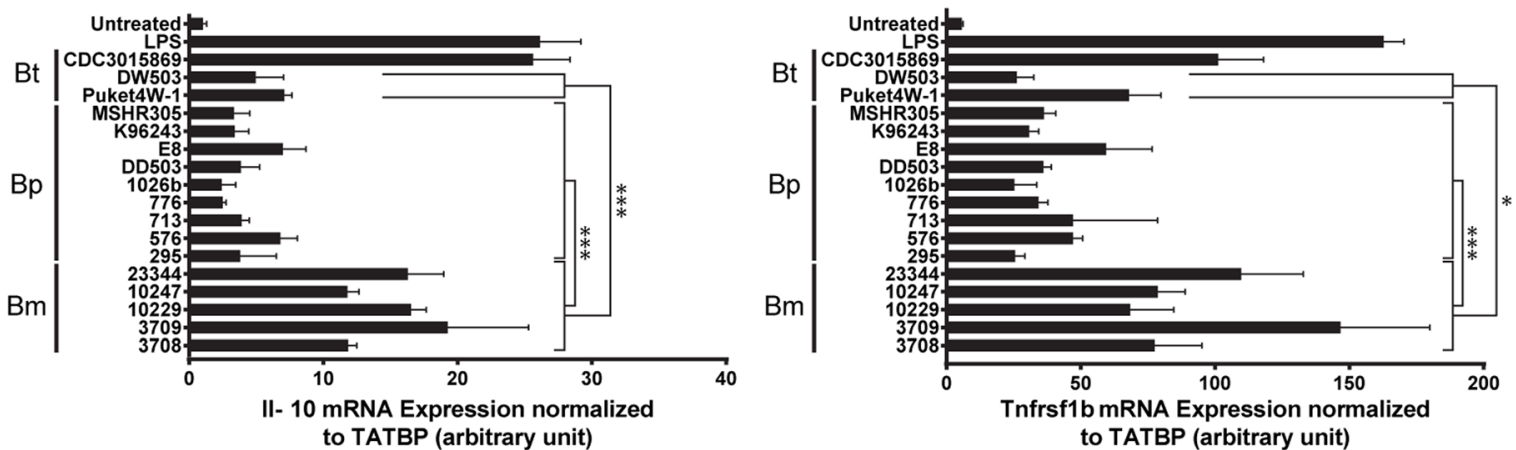

Fig. 7 (See legend on next page.) 
(See figure on previous page.)

Fig. 7 Heat map of pairwise differential gene expression and validation a) Heat maps are colored spectrally to indicate strength of statistical significance for pairwise comparisons. Spectral colors range from red (negative) to yellow (positive) for the t-statistic of each Student's $t$-tests. Gray regions indicate absence of statistically significant differences in gene expression. Data for the $8 \mathrm{~h}$ time post infection is shown. b) mRNA was extracted from independently prepared RAW264.7 macrophages infected with Burkholderia spp. for eight hours. mRNA was reverse transcribed to cDNA and the expression levels of indicated genes were quantified by real-time PCR. (* and ${ }^{* * *}$ represent $p$ value smaller than 0.05 and 0.001 , respectively). The data is average of three independent experiments

cluster (nuclei per cluster $>3$ ). The percentage of MNGC was calculated as (Number of MNGC objects)/(Number of Cluster objects)*100. The number of nuclei represents the total number of cells that were imaged and data acquired.

\section{Statistical analysis of the High Content Imaging data}

While a majority of the data was approximately normal, there were a few data points that were apparent outliers. In order to obtain accurate estimates of the means and standard deviations that were not unduly influenced by these extreme data points, a robust Bayesian approach was used that fit a $t$ distribution to the residual error. Using $t$-distributed error rather than normal error allows the use of the degrees of freedom parameter, $v$, to act as a normality parameter that is low in the presence of outliers and high when the data are more normal. Let $i$ index Day, $j$ index Plate, and $k$ index strain, then the Day effect was fit first using the following model:

$$
y_{i j k} \sim t\left(\mu_{i}, \sigma_{i}, v_{i}\right)
$$

Where $y_{i j k}$ is the response on the $i^{\text {th }}$ day, the $j^{\text {th }}$ plate, and the $k^{t h}$ plate, $\mu_{i}$ is the mean effect for day $i, \sigma_{i}$ is the standard deviation, and $v_{i}$ is the normality parameter. The priors are

$$
\begin{aligned}
& \mu_{i} \sim \text { Normal }\left(\frac{\bar{y}}{1000}, 1000 \cdot \hat{\sigma}_{y}^{2}\right) \\
& \sigma_{i} \sim \text { Uniform }\left(\frac{\hat{\sigma}_{y}^{2}}{1000}, 1000 \cdot \hat{\sigma}_{y}^{2}\right) \\
& v_{i} \sim \text { Exponential }\left(\frac{1}{29}, 1\right)
\end{aligned}
$$

The prior for $v_{i}$ is a shifted exponential with lower bound at 1 . After fitting the Day effect, the median of the posterior distribution of $\mu_{i}$ is subtracted from $y_{i j k}$ and that difference, $y_{i j k}^{(1)}$, is fit using the same methods for the Plate effect, with the median of the distribution of the average Plate effect, $\mu_{j}$, subtracted from $y_{i j k}^{(1)}$, and the result, $y_{i j k}^{(2)}$ is used to fit the Strain effect using the same method.

The posterior distributions of the mean Strain effect are plotted in violin plots. Posterior distributions represent the probability distribution of the parameter and confidence intervals are derived using the quantiles of the posterior. Violin plots are more informative as to the actual distribution, with the thickest portions of the violin plot representing the highest probability regions for the parameter - in this case the mean of the strain effect. Taller thinner violin plots represent estimates that are more variable and less certain than shorter wider violin plots on the same scale.

\section{Gene transcription analysis using Real-time PCR}

RAW264.7 macrophages $\left(1 \times 10^{6}\right.$ cells/well) were untreated (negative control), treated with $1 \mu \mathrm{g} / \mathrm{ml}$ Escherichia coli LPS (Life Technology, Carlsbad, CA) or infected with Burkholderia spp. at a MOI of 10. At 4 and $8 \mathrm{~h}$ post-infection, RNA was isolated from RAW264.7 macrophages using Trizol $^{\oplus}$ (Life Technology, Carlsbad, CA) according to the manufacturer's protocol. Approximately $1 \mu \mathrm{g}$ of purified RNA was subjected to genomic DNA elimination and cDNA synthesis using the $\mathrm{RT}^{2}$ first strand kit (Qiagen, Valencia, CA). cDNA was added to $\mathrm{RT}^{2}$ qPCR master mix and $25 \mu \mathrm{l}$ was added to each well of a $\mathrm{RT}^{2}$ profiler mouse inflammatory chemokines and receptors plate (Qiagen, Valencia, CA). PCR amplification was performed using Applied Biosystems 7900 HT Real-time PCR instrument (Life Technology, Carlsbad, CA).

\section{Statistical analysis of the real-time PCR data}

The raw Ct (threshold cycle) data for 84 inflammationrelated genes in Burkholderia-infected RAW264.7 macrophages were corrected for housekeeping genes to yield a $\Delta \mathrm{Ct}$ dataset. This data was further corrected by subtracting the average values for the untreated controls for the 4 and $8 \mathrm{~h}$ time points $(\Delta \Delta \mathrm{Ct}) . \Delta \Delta \mathrm{Ct}$ values were $\mathrm{z}$ scored (absolute deviation) normalized within each strain and hierarchically clustered (Manhattan distance calculation and a Wards linkage method) across gene expression $(\mathrm{N}=84)$ and Burkholderia strains $(\mathrm{N}=20)$. Selective grouping of neighboring branches within the cluster dendrogram for Burkholderia strains was used to determine sub-clade members that yield significant ( $\mathrm{p}<=0.05)$ differences in gene expression when compared to other sub-clade members (this procedure is automatically implemented within the pvclust package in the R Programming Language) [64]. This method reduced the original dendrogram of 20 Burkholderia strains and E. coli LPS control into 11 sub-clades. The 
fidelity of these 11 sub-clades was evaluated using linear discriminant analysis (lda), neural nets (nn) and random forests (rf). The consensus amongst these methods found general agreement, with exact predictions for all but 3 of the 11 sub-clades, and a positive predictive value of greater than 0.6 for the exceptions. A separate application of stepwise linear anova regression modeling (sub-clades(1-11) gene expression) yields a multiple Rsquared value of 0.9706 and an adjusted $R$-squared value of 0.9366, corresponding to an F-statistic of 28.53 and a $p$-value of $2.811 \mathrm{e}-10$. The magnitude of this $p$-value further supports the classification of Burkholderia strains into sub-clades (1-11). Grouping gene expressions according to sub-clades (1-11), and performing all-to-all pairwise Student's $t$-test (number of pairwise comparisons $=11^{*} 10 / 2=55$ ), is used to identify genes having a significantly $(\mathrm{p}<0.05)$ different expression between at least one pair of sub-clades.

\section{Quantitation of cytokine production}

RAW264.7 macrophages $\left(1 \times 10^{6}\right.$ cells/well $)$ were infected with indicated Burkholderia spp. at a MOI of 10. Eight hours post infection, supernatants were collected and filtered using low protein binding $0.2 \mu \mathrm{m}$ filters. Mouse cytokines were measured using MesoScale Discovery Ultrasensitive pro-inflammatory 7-plex plates with an I2400 plate-reader (Meso Scale Discovery, Gaithersburg, Maryland).

\section{Comparative Genomics analyses of Burkholderia spp.}

A nucleotide-level BLAST (NCBI) was used to identify putative orthologs of virulence factors within each of the available genomes. When divergence was seen between the query sequence and the subject genome, a modified version of Psi-Fi was used to identify to mutations that would likely result in the loss of gene function [65]. NCTC10229 (NC_008835-NC_008836) was used as the query strain for all $B$. mallei genomes (Bm NCTC 10247 and Bm NCTC 3709) and K96243 (NC_006350NC_006351) was used as the query strain for all Bp genomes (Bp 576, Bp 1026b) (Additional file 5: Table S2). Bp 295, Bp DD50, Bp 776 and Bp 713 were not included in the analysis due to the lack of sequence availability.

\section{Transmission Electron Microscopy (TEM)}

RAW264.7 macrophages $\left(2 \times 10^{6}\right.$ cells/well $)$ were infected with Bp K96243 and Bp 776 at MOI 10. After 2 h incubation, cells were washed $2 \mathrm{x}$ and media containing $250 \mathrm{ug} / \mathrm{ml} \mathrm{KAN}$ was added to kill extracellular bacteria. Cells were scraped with a cell lifter, washed, pelleted, and fixed at room temperature for $1 \mathrm{~h}$ in TEM primary fixatives $(2.5 \%$ formaldehyde, $2.5 \%$ glutaraldehyde in $0.1 \mathrm{M}$ sodium cacodylate $\mathrm{pH} 7.4$ buffer) at each of the following time points: $2,4,6$, and $8 \mathrm{~h}$. Cells were then washed three times in $0.1 \mathrm{M}$ sodium cacodylate buffer for $10 \mathrm{~min}$ each, the primary fixed cells were then incubated with $1 \%$ Osmium Tetroxide in $0.1 \mathrm{M}$ Sodium Cacodylate for $1 \mathrm{~h}$. After washing with distilled water three times for $10 \mathrm{~min}$ each, fixed cells were stained in $1 \%$ uranyl acetate for $1 \mathrm{~h}$ and dehydrated in ethanol series of 22, 50, 75 and $95 \%$ successively for $10 \mathrm{~min}$ each. The cells were dehydrated three times for $10 \mathrm{~min}$ each in $100 \%$ ethanol and then two times for $10 \mathrm{~min}$ each in propylene oxide. Cells were infiltrated in well mixed 50 \% propylene oxide, 50 \% Epon812 (Electron Microscopy Sciences, RT14120) for $1 \mathrm{~h}$ with agitation at room temperature followed by $100 \%$ Epon 8123 times for $1 \mathrm{~h}$ each with agitation. After which the samples were placed in an oven and allowed to polymerize at $60{ }^{\circ} \mathrm{C}$ for $24 \mathrm{~h}$. Thin sections (approximately $80 \mathrm{~nm}$ ) were collected and pre-stained with $1 \%$ uranyl acetate and Sato lead before examination in a JEOL 1011 transmission electron microscope at $80 \mathrm{kv}$ and digital images were acquired using AMT camera system.

\section{Ethics statement}

As no human or animal subjects were used for this work consent and ethical approval was not required.

\section{Availability of supporting data}

\section{Additional files}

Additional file 1: Figure S1. Bp K96243 and Bp 776 escape from membrane bound vesicles. (A) RAW264.7 macrophages were infected by either Bp 776 or Bp K96243 at indicated time points. Samples were prepared and subjected to TEM as described in the methods section. The scale bar represents $0.5 \mu \mathrm{m}$. Arrows indicate bacteria. (B) A total number of 25 cells were examined to determine the number of $\mathrm{Bp}$ that reside either inside or outside of membrane bound vesicles. (TIFF $3607 \mathrm{~kb}$ )

Additional file 2: Figure S2. Statistical analysis of the cellular attributes of the MNGC formation. Paired Student's $t$-test was performed to evaluate the probability that the mean value of the strain listed in the column is greater than the strain listed in the row for the feature \% MNGC formation. Data for the $10 \mathrm{~h}$ post infection is shown. (TIFF $160 \mathrm{~kb}$ )

Additional file 3: Figure S3. Statistical analysis of cytokine production in RAW264.7 macrophages infected with Burkholderia spp. Paired Student's $t$-test was performed to evaluate the statistical significance of differential cytokine productions after infecting RAW264.7 macrophages with indicated Burkholderia spp. (TIFF $571 \mathrm{~kb}$ )

Additional file 4: Table S1. Hierarchical clustering of the inflammation related gene expression data. This is the underlying data for Fig. 6. The raw Ct data for 84 inflammation-related genes in Burkholderia-infected RAW264.7 macrophages were corrected for housekeeping genes to yield a $\Delta$ Ct dataset. This data was further corrected by subtracting the average values for the untreated controls for the 4 and $8 \mathrm{~h}$ time points $(\Delta \Delta \mathrm{Ct})$. $\Delta \Delta \mathrm{Ct}$ values were $\mathrm{z}$-score (absolute deviation) normalized within each strain. Explanation of the column headings: column B to column AQ represents the name of the Burkholderia strain and the time point at which the expression of genes were assayed. (XLSX $50 \mathrm{~kb}$ )

Additional file 5: Table S2. Pairwise comparison of $p$-values between Burkholderia strain for each gene at 4 and $8 \mathrm{~h}$. Column headings specify gene, strain 1, strain 2, p-value, t-statistic and exposure time. Left and right columns correspond to the 4 and $8 \mathrm{~h}$ exposure times, respectively. 
T-statistic is based on comparisons of strain 1 to strain 2. P-values less than 0.2 are listed. (XLSX $16 \mathrm{~kb}$ )

Additional file 6: Table S3. A list of loci examined in comparative genomic study. (XLSX $17 \mathrm{~kb}$ )

Additional file 7: Table S4. UCC nomenclature for the different Burkholderia spp. Explanation of the column headings: Burkholderia Species: names of the species used in this study; Strain names: names of the strains; UCC nomenclature: the corresponding nomenclature used within USAMRIII. (XLSX $10 \mathrm{~kb}$ )

\section{Abbreviations}

Bm: Burkholderia mallei; Bo: Burkholderia oklahomensis; Bp: Burkholderia pseudomallei; Bt: Burkholderia thailandensis; CFU: Colony forming unit; CHBP: Cif homolog in $\mathrm{Bp} ; \mathrm{HCl}$ : High-content imaging; IFN: Interferon; LPS: lipopolysaccharide; MNGC: Multinucleated giant cell; NHP: Non-human primate; NLR: NOD-like receptor; PBMC: Peripheral blood mononuclear cell; PHD: Prolyl hydroxylase; PRR: Pathogen recognition receptor; T3SS: Type III secretion system; T6SS: Type VI secretion system; TCA: Tricarboxylic acid; TEM: Transmission electron microscopy; TLR: Toll-like receptor.

\section{Competing interests}

The authors declare that they have no competing interests.

\section{Authors' contributions}

CYC, RLU and RGP prepared the manuscript. CYC, SB, RLU and RGP designed the experiments and interpreted data. KK, RR, SM, MPU, BE, JFO, DJL, KPK, TAK and MJW performed the experiments. JTL performed Comparative Genomics analyses. SPD and DC performed the statistical analysis. MJW provided bacteria strains. The final manuscript was read and approved by all authors.

\section{Acknowledgments}

We would like to thank Oak Ridge Institute for Science and Education for participating in the Postgraduate Research Program at the U.S. Army Medical Research and Materiel Command. Opinions, interpretations, conclusions, and recommendations are those of the authors and are not necessarily endorsed by the U.S. Army, nor does mention of trade names, commercial products, or organizations imply endorsement by the U.S. Government.

\section{Author details}

${ }^{1}$ Molecular and Translational Sciences Division, United States Army Medical Research Institute of Infectious Diseases (USAMRIID), Fort Detrick, MD, USA. ${ }^{2}$ Institute for Therapeutic Innovation, Department of Medicine, University of Florida, Orlando, FL, USA. ${ }^{3}$ Florida SouthWestern State College, Fort Myers, FL, USA. ${ }^{4}$ Perkin Elmer, Waltham, MA, USA. ${ }^{5}$ Center for Genome Sciences, USAMRIII, Fort Detrick, MD, USA. ${ }^{6}$ Office of Regulated Studies, USAMRIII, Fort Detrick, MD, USA. ${ }^{7}$ Pathology Division, USAMRIID, Fort Detrick, MD, USA. ${ }^{8}$ Diagnostic Systems Division, USAMRIID, Fort Detrick, MD, USA. ${ }^{9}$ Screening Technologies Branch, Developmental Therapeutics Program, National Cancer Institute, Frederick, MD, USA.

\section{Received: 26 March 2015 Accepted: 28 October 2015} Published online: 06 November 2015

\section{References}

1. Galyov EE, Brett PJ, DeShazer D. Molecular insights into Burkholderia pseudomallei and Burkholderia mallei pathogenesis. Annu Rev Microbiol. 2010;64:495-517.

2. Sprague LD, Neubauer $H$. Melioidosis in animals: a review on epizootiology, diagnosis and clinical presentation. J Vet Med B Infect Dis Vet Public Health. 2004;51(7):305-20.

3. White NJ. Melioidosis. Lancet. 2003;361(9370):1715-22.

4. Wiersinga WJ, Currie BJ, Peacock SJ. Melioidosis. N Engl J Med. 2012;367(11):1035-44.

5. Godoy D, Randle G, Simpson AJ, Aanensen DM, Pitt TL, Kinoshita R, et al. Multilocus sequence typing and evolutionary relationships among the causative agents of melioidosis and glanders, Burkholderia pseudomallei and Burkholderia mallei. J Clin Microbiol. 2003;41(5):2068-79.

6. Whitlock GC, Estes DM, Torres AG. Glanders: off to the races with Burkholderia mallei. FEMS Microbiol Lett. 2007;277(2):115-22.
7. Neubauer H, Sprague LD, Zacharia R, Tomaso H, Al Dahouk S, Wernery R, et al. Serodiagnosis of Burkholderia mallei infections in horses: state-of-the-art and perspectives. J Vet Med B Infect Dis Vet Public Health. 2005;52(5):201-5.

8. Schell MA, Ulrich RL, Ribot WJ, Brueggemann EE, Hines HB, Chen D, et al. Type $\mathrm{VI}$ secretion is a major virulence determinant in Burkholderia mallei. Mol Microbiol. 2007;64(6):1466-85.

9. Glass MB, Steigerwalt AG, Jordan JG, Wilkins PP, Gee JE. Burkholderia oklahomensis sp. nov., a Burkholderia pseudomallei-like species formerly known as the Oklahoma strain of Pseudomonas pseudomallei. Int J Syst Evol Microbiol. 2006;56(Pt 9):2171-6.

10. Brett PJ, DeShazer D, Woods DE. Burkholderia thailandensis sp. nov., a Burkholderia pseudomallei-like species. Int J Syst Bacteriol. 1998;48 Pt 1:317-20.

11. McCormick JB, Weaver RE, Hayes PS, Boyce JM, Feldman RA. Wound infection by an indigenous Pseudomonas pseudomallei-like organism isolated from the soil: case report and epidemiologic study. J Infect Dis. 1977;135(1):103-7.

12. Deshazer D. Virulence of clinical and environmental isolates of Burkholderia oklahomensis and Burkholderia thailandensis in hamsters and mice. FEMS Microbiol Lett. 2007;277(1):64-9.

13. Chaiyaroj SC, Kotrnon K, Koonpaew S, Anantagool N, White NJ, Sirisinha S. Differences in genomic macrorestriction patterns of arabinose-positive (Burkholderia thailandensis) and arabinose-negative Burkholderia pseudomallei. Microbiol Immunol. 1999;43(7):625-30.

14. Wuthiekanun V, Anuntagool N, White NJ, Sirisinha S. Short report: a rapid method for the differentiation of Burkholderia pseudomallei and Burkholderia thailandensis. AmJTrop Med Hyg. 2002;66(6):759-61.

15. Harley VS, Dance DA, Tovey G, McCrossan MV, Drasar BS. An ultrastructural study of the phagocytosis of Burkholderia pseudomallei. Microbios. 1998;94(377):35-45.

16. Jones AL, Beveridge TJ, Woods DE. Intracellular survival of Burkholderia pseudomallei. Infect Immun. 1996;64(3):782-90.

17. Allwood EM, Devenish RJ, Prescott M, Adler B, Boyce JD. Strategies for Intracellular Survival of Burkholderia pseudomallei. Front Microbiol. 2011;2:170.

18. Breitbach K, Rottner K, Klocke S, Rohde M, Jenzora A, Wehland J, et al. Actin-based motility of Burkholderia pseudomallei involves the Arp 2/3 complex, but not N-WASP and Ena/NASP proteins. Cell Microbiol. 2003;5(6):385-93.

19. Kespichayawattana W, Rattanachetkul S, Wanun T, Utaisincharoen P, Sirisinha S. Burkholderia pseudomallei induces cell fusion and actinassociated membrane protrusion: a possible mechanism for cell-to-cell spreading. Infect Immun. 2000;68(9):5377-84.

20. Stevens MP, Stevens JM, Jeng RL, Taylor LA, Wood MW, Hawes P, et al. Identification of a bacterial factor required for actin-based motility of Burkholderia pseudomallei. Mol Microbiol. 2005;56(1):40-53.

21. Pilatz S, Breitbach $K$, Hein N, Fehlhaber B, Schulze J, Brenneke B, et al. Identification of Burkholderia pseudomallei genes required for the intracellular life cycle and in vivo virulence. Infect Immun. 2006;74(6):3576-86.

22. Stevens JM, Galyov EE, Stevens MP. Actin-dependent movement of bacterial pathogens. Nat Rev Microbiol. 2006;4(2):91-101.

23. French CT, Toesca IJ, Wu TH, Teslaa T, Beaty SM, Wong W, et al. Dissection of the Burkholderia intracellular life cycle using a photothermal nanoblade. Proc Natl Acad Sci U S A. 2011;108(29):12095-100.

24. Sun GW, Chen Y, Liu Y, Tan GY, Ong C, Tan P, et al. Identification of a regulatory cascade controlling Type III Secretion System 3 gene expression in Burkholderia pseudomallei. Mol Microbiol. 2010;76(3):677-89.

25. Chen $Y$, Schroder I, French $C T$, Jaroszewicz A, Yee XJ, Teh BE, et al. Characterization and analysis of the Burkholderia pseudomallei BsaN virulence regulon. BMC Microbiol. 2014;14:206.

26. Stone JK, DeShazer D, Brett PJ, Burtnick MN. Melioidosis: molecular aspects of pathogenesis. Expert Rev Anti-Infect Ther. 2014;12(12):1487-99.

27. Cheng AC, Currie BJ. Melioidosis: epidemiology, pathophysiology, and management. Clin Microbiol Rev. 2005;18(2):383-416.

28. Silva EB, Dow SW. Development of Burkholderia mallei and pseudomalle vaccines. Front Cell Infect Microbiol. 2013;3:10.

29. Wiersinga WJ, Wieland CW, Dessing MC, Chantratita N, Cheng AC, Limmathurotsakul D, et al. Toll-like receptor 2 impairs host defense in gram-negative sepsis caused by Burkholderia pseudomallei (Melioidosis). PLoS Med. 2007;4(7):e248.

30. Goodyear A, Bielefeldt-Ohmann H, Schweizer H, Dow S. Persistent gastric colonization with Burkholderia pseudomallei and dissemination from the 
gastrointestinal tract following mucosal inoculation of mice. PLoS One. 2012;7(5):e37324

31. Goodyear A, Troyer R, Bielefeldt-Ohmann H, Dow S. MyD88-dependent recruitment of monocytes and dendritic cells required for protection from pulmonary Burkholderia mallei infection. Infect Immun. 2012;80(1):110-20.

32. Goodyear A, Jones A, Troyer R, Bielefeldt-Ohmann H, Dow S. Critical protective role for MCP-1 in pneumonic Burkholderia mallei infection. J Immunol. 2010;184(3):1445-54.

33. Goodyear A, Kellihan L, Bielefeldt-Ohmann H, Troyer R, Propst K, Dow S. Protection from pneumonic infection with burkholderia species by inhalational immunotherapy. Infect Immun. 2009;77(4):1579-88.

34. Aachoui Y, Leaf IA, Hagar JA, Fontana MF, Campos CG, Zak DE, et al. Caspase-11 protects against bacteria that escape the vacuole. Science. 2013;339(6122):975-8.

35. Chin CY, Monack DM, Nathan S. Genome wide transcriptome profiling of a murine acute melioidosis model reveals new insights into how Burkholderia pseudomallei overcomes host innate immunity. BMC Genomics. 2010;11:672.

36. Morris J, Williams N, Rush C, Govan B, Sangla K, Norton R, et al. Burkholderia pseudomallei triggers altered inflammatory profiles in a whole-blood model of type 2 diabetes-melioidosis comorbidity. Infect Immun. 2012;80(6):2089-99.

37. Panomket P. Immune response to Burkholderia pseudomallei. J Med Assoc Thai. 2011;94(11):1410-7.

38. Suwannasaen D, Mahawantung J, Chaowagul W, Limmathurotsakul D, Felgner PL, Davies $\mathrm{H}$, et al. Human immune responses to Burkholderia pseudomallei characterized by protein microarray analysis. J Infect Dis. 2011;203(7):1002-11.

39. Tan KS, Chen Y, Lim YC, Tan GY, Liu Y, Lim YT, et al. Suppression of host innate immune response by Burkholderia pseudomallei through the virulence factor TssM. J Immunol. 2010;184(9):5160-71.

40. Cui J, Yao Q, Li S, Ding X, Lu Q, Mao H, et al. Glutamine deamidation and dysfunction of ubiquitin/NEDD8 induced by a bacterial effector family. Science. 2010;329(5996):1215-8.

41. Nierman WC, DeShazer D, Kim HS, Tettelin H, Nelson KE, Feldblyum T, et al. Structural flexibility in the Burkholderia mallei genome. Proc Natl Acad Sci U S A. 2004;101(39):14246-51.

42. Burtnick MN, Brett PJ, Harding SV, Ngugi SA, Ribot WJ, Chantratita N, et al. The cluster 1 type $\mathrm{VI}$ secretion system is a major virulence determinant in Burkholderia pseudomallei. Infect Immun. 2011;79(4):1512-25.

43. Welkos SL, Klimko CP, Kern SJ, Bearss JJ, Bozue JA, Bernhards RC, et al. Characterization of Burkholderia pseudomallei Strains Using a Murine Intraperitoneal Infection Model and In Vitro Macrophage Assays. PLoS One. 2015;10(4):e0124667.

44. Wand ME, Muller CM, Titball RW, Michell SL. Macrophage and Galleria mellonella infection models reflect the virulence of naturally occurring isolates of B. pseudomallei, B. thailandensis and B. oklahomensis. BMC Microbiol. 2011;11(1):11.

45. Stevens MP, Wood MW, Taylor LA, Monaghan P, Hawes P, Jones PW, et al. An Inv/Mxi-Spa-like type III protein secretion system in Burkholderia pseudomallei modulates intracellular behaviour of the pathogen. Mol Microbiol. 2002;46(3):649-59.

46. Stevens MP, Friebel A, Taylor LA, Wood MW, Brown PJ, Hardt WD, et al. A Burkholderia pseudomallei type III secreted protein, BopE, facilitates bacterial invasion of epithelial cells and exhibits guanine nucleotide exchange factor activity. J Bacteriol. 2003;185(16):4992-4996.

47. Ceballos-Olvera I, Sahoo M, Miller MA, Del Barrio L, Re F. Inflammasomedependent pyroptosis and IL-18 protect against Burkholderia pseudomallei lung infection while IL-1beta is deleterious. PLoS Pathog. 2011;7(12):e1002452.

48. Pegoraro G, Eaton BP, Ulrich RL, Lane DJ, Ojeda JF, Bavari S, et al. A highcontent imaging assay for the quantification of the Burkholderia pseudomallei induced multinucleated giant cell (MNGC) phenotype in murine macrophages. BMC Microbiol. 2014;14:98

49. Friedland JS, Suputtamongkol Y, Remick DG, Chaowagul W, Strieter RM, Kunkel SL, et al. Prolonged elevation of interleukin-8 and interleukin-6 concentrations in plasma and of leukocyte interleukin- 8 mRNA levels during septicemic and localized Pseudomonas pseudomallei infection. Infect Immun. 1992;60(6):2402-8.

50. Brown AE, Dance DA, Suputtamongkol Y, Chaowagul W, Kongchareon S, Webster HK, et al. Immune cell activation in melioidosis: increased serum levels of interferon-gamma and soluble interleukin-2 receptors without change in soluble CD8 protein. J Infect Dis. 1991;163(5):1145-8.
51. Suputtamongkol Y, Kwiatkowski D, Dance DA, Chaowagul W, White NJ. Tumor necrosis factor in septicemic melioidosis. J Infect Dis. 1992;165(3):561-4.

52. Ulett GC, Ketheesan N, Hirst RG. Cytokine gene expression in innately susceptible BALB/C mice and relatively resistant C57BL/6 mice during infection with virulent Burkholderia pseudomallei. Infect Immun. 2000;68(4):2034-42.

53. Sitthidet C, Korbsrisate S, Layton AN, Field TR, Stevens MP, Stevens JM. Identification of motifs of Burkholderia pseudomallei BimA required for intracellular motility, actin binding, and actin polymerization. J Bacteriol. 2011;193(8):1901-10.

54. Tan GY, Liu Y, Sivalingam SP, Sim SH, Wang D, Paucod JC, et al. Burkholderia pseudomallei aerosol infection results in differential inflammatory responses in BALB/C and C57BI/6 mice. J Med Microbiol. 2008;57(Pt 4):508-15.

55. Liu B, Koo GC, Yap EH, Chua KL, Gan YH. Model of differential susceptibility to mucosal Burkholderia pseudomallei infection. Infect Immun. 2002;70(2):504-11.

56. Vesna Milacic VM, Schwendeman SP. Lysozyme release and polymer erosion behavior of injectable implants prepared from PLGA-PEG block copolymers and PLGA/PLGA-PEG blends. Pharm Res. 2014;31(2):436-48.

57. Lower M, Schneider G. Prediction of type III secretion signals in genomes of gram-negative bacteria. PLoS One. 2009;4(6):e5917.

58. Alam S, Amemiya K, Bernhards RC, Ulrich RG, Waag DM, Saikh KU. Characterization of cellular immune response and innate immune signaling in human and nonhuman primate primary mononuclear cells exposed to Burkholderia mallei. Microb Pathog. 2014;78C:20-8.

59. Tannahill GM, Curtis AM, Adamik J, Palsson-McDermott EM, McGettrick AF, Goel G, et al. Succinate is an inflammatory signal that induces IL-1beta through HIF-1alpha. Nature. 2013:496(7444):238-42.

60. Haneklaus M, O'Neill LA. NLRP3 at the interface of metabolism and inflammation. Immunol Rev. 2015;265(1):53-62.

61. Heine HS, England MJ, Waag DM, Byrne WR. In vitro antibiotic susceptibilities of Burkholderia mallei (causative agent of glanders) determined by broth microdilution and E-test. Antimicrob Agents Chemother. 2001;45(7):2119-21.

62. Burtnick MN, DeShazer D, Nair V, Gherardini FC, Brett PJ. Burkholderia mallei cluster 1 type $\mathrm{VI}$ secretion mutants exhibit growth and actin polymerization defects in RAW 264.7 murine macrophages. Infect Immun. 2010;78(1):88-99.

63. Kota KP, Eaton B, Lane D, Ulrich M, Ulrich R, Peyser BD, et al. Integrating high-content imaging and chemical genetics to probe host cellular pathways critical for Yersinia pestis infection. PLoS One. 2013;8(1):e55167.

64. Shimodaira $\mathrm{H}$. Approximately unbiased tests of regions using multistepmultiscale bootstrap resampling. Ann Stat. 2004;32(6):2616-41.

65. Lerat E, Ochman H. Psi-Phi: exploring the outer limits of bacterial pseudogenes. Genome Res. 2004;14(11):2273-8.

66. Haraga A, West TE, Brittnacher MJ, Skerrett SJ, Miller SI. Burkholderia thailandensis as a model system for the study of the virulence-associated type III secretion system of Burkholderia pseudomallei. Infect Immun. 2008;76(11):5402-11.

67. Stevens JM, Ulrich RL, Taylor LA, Wood MW, Deshazer D, Stevens MP, et al. Actin-binding proteins from Burkholderia mallei and Burkholderia thailandensis can functionally compensate for the actin-based motility defect of a Burkholderia pseudomallei bimA mutant. J Bacteriol. 2005;187(22):7857-62.

68. Brett PJ, Burtnick MN, Su H, Nair V, Gherardini FC. iNOS activity is critical for the clearance of Burkholderia mallei from infected RAW 264.7 murine macrophages. Cell Microbiol. 2008;10(2):487-98.

69. Campos CG, Byrd MS, Cotter PA. Functional characterization of Burkholderia pseudomallei trimeric autotransporters. Infect Immun. 2013;81(8):2788-99.

\section{Submit your next manuscript to BioMed Central and take full advantage of:}

- Convenient online submission

- Thorough peer review

- No space constraints or color figure charges

- Immediate publication on acceptance

- Inclusion in PubMed, CAS, Scopus and Google Scholar

- Research which is freely available for redistribution 